\title{
Osseous versus Nonosseous Spinal Epidural Arteriovenous Fistulas: Experiences of 13 Patients
}

\author{
(D) Y. Song, (D).H. Cho, (DD.W. Lee, (D).J. Sheen, (D).H. Shin, and (DD.C. Suh
} O- $=$

\begin{abstract}
BACKGROUND AND PURPOSE: Spinal epidural arteriovenous fistulas are rare vascular malformations. We present 13 patients with spinal epidural arteriovenous fistulas, noting the various presenting symptom patterns, imaging findings related to bone involvement, and outcomes.

MATERIALS AND METHODS: Among 111 patients with spinal vascular malformations in the institutional data base from 1993 to 2017, thirteen patients (11.7\%) had spinal epidural arteriovenous fistulas. We evaluated presenting symptoms and imaging findings, including bone involvement and mode of treatment. To assess the treatment outcome, we compared initial and follow-up clinical status using the modified Aminoff and Logue Scale of Disability and the modified Rankin Scale.

RESULTS: The presenting symptoms were lower back pain $(n=2)$, radiculopathy $(n=5)$, and myelopathy $(n=7)$. There is overlap of symptoms in 1 patient (No. 11). Distribution of spinal epidural arteriovenous fistulas was cervical $(n=3)$, thoracic $(n=2)$, lumbar $(n=6)$, and sacral $(n=2)$. Intradural venous reflux was identified in 7 patients with congestive venous myelopathy. The fistulas were successfully treated in all patients who underwent treatment (endovascular embolization, $n=10$; operation, $n=1$ ) except 2 patients who refused treatment due to tolerable symptoms. Transarterial glue $(n=7)$ was used in nonosseous types; and transvenous coils $(n=3)$, in osseous type. After 19 months of median follow-up, the patients showed symptom improvement after treatment.
\end{abstract}

CONCLUSIONS: Although presenting symptoms were diverse, myelopathy caused by intradural venous reflux was the main target of treatment. Endovascular treatment was considered via an arterial approach in nonosseous types and via a venous approach in osseous types.

ABBREVIATIONS: ALS = Aminoff and Logue Scale of Disability; SDAVF = spinal dural arteriovenous fistula; SEDAVF = spinal epidural arteriovenous fistula; TAE $=$ transarterial embolization; TVE = transvenous embolization

$\boldsymbol{S}_{\mathrm{ala}}^{\mathrm{p}}$ pinal epidural arteriovenous fistula (SEDAVF) is a rare vascuar disease of the spine that manifests with benign symptoms, such as radiculopathy. ${ }^{1,2}$ Because of advances in imaging techniques, such as $3 \mathrm{D}$ rotational spinal angiography, and improvement in the understanding of the anatomy of spinal vascular lesions, SEDAVFs are diagnosed with increasing frequency. ${ }^{3,4}$

Received June 14, 2018; accepted October 12.

From the Departments of Radiology and Research Institute of Radiology (Y.S., D.W.L., J.J.S., J.H.S., D.C.S.), University of Ulsan, College of Medicine, Asan Medical Center, Seoul, Republic of Korea; and Department of Neurosurgery (S.H.C.), Ulsan University College of Medicine, Asan Hospital, Gang-reung, Republic of Korea. This work was supported by the National Research Foundation of Korea grant funded by the Korean government (No. 2018R1A2B6003143).

Please address correspondence to Dae Chul Suh, MD, PhD, Department of Radiology, Asan Medical Center, University of Ulsan, College of Medicine, 88, Olympic-ro 43-gil, Songpa-gu, Seoul 05505, Korea; e-mail: dcsuh@amc.seoul.kr

-- Indicates open access to non-subscribers at www.ajnr.org

三 Indicates article with supplemental on-line table.

http://dx.doi.org/10.3174/ajnr.A5904
SEDAVFs are fistulas located in the epidural space between the branches of the radicular artery (mostly dorsal somatic branches) and the epidural venous plexus, ${ }^{4,5}$ whereas the typical location of more common spinal dural arteriovenous fistulas (SDAVFs) is within the dural sleeve between the radiculomeningeal artery and the radicular vein or bridging vein. ${ }^{4}$ In most cases of SEDAVFs, the venous flow drains only to the epidural and paravertebral plexuses, and the lesion is generally asymptomatic until dilation of arterialized veins causes compressive symptoms or intradural reflux occurs. ${ }^{5}$ Differentiation from other spinal vascular pathology, including SDAVF, is mandatory to localize the exact cause of presenting symptoms. ${ }^{6,7}$

SEDAVFs can be categorized into 2 distinct presenting symptom patterns, depending on the involvement of the intradural vein. ${ }^{8}$ With intradural venous reflux, they may mimic SDAVFs with symptoms of congestive myelopathy such as lower leg weakness and sphincter dysfunction. ${ }^{6,9-11}$ In SEDAVFs without intradural venous drainage, compressive radiculopathy or myelopathy caused by epidural vascular lesions may be the main problem. ${ }^{12}$ 
Endovascular embolization, an operation, and combined therapy have been the main treatment methods for SEDAVFs. Although various endovascular treatment options in terms of approach routes and embolic materials have been reported, ${ }^{2}$ the best treatment method has not been determined because of the complex anatomy of the target lesion. An understanding of the manifestations and anatomy of the lesion is the key to accurate diagnosis and proper management. ${ }^{13}$ We present 13 cases of SEDAVF from Asan Medical Center, studying their various clinical manifestations, radiologic features, and outcomes after endovascular treatment.

\section{MATERIALS AND METHODS}

\section{Patients}

We retrospectively reviewed a data base of our institution, a tertiary hospital, that was maintained prospectively since 1993 to identify all spinal vascular malformations (ie, spinal arteriovenous malformation, spinal dural/epidural arteriovenous fistula, and vertebrovertebral fistula). Among 111 spinal vascular malformations diagnosed at our neurointervention suite from January 1993 to April 2017, we included 13 patients with SEDAVFs. The diagnosis was confirmed by high-resolution selective spinal angiography. Patient information regarding the clinical history, neurologic symptoms and signs, and follow-up results was obtained from the data base connected to the electronic medical record. Patients' symptoms were classified as myelopathy and radiculopathy according to the initial neurologic symptoms and signs. "Myelopathy" was defined as spinal cord symptoms with gait disturbance, motor/sensory deficits, or urinary/bowel sphincter dysfunction; "radiculopathy" was defined as a series of symptoms along the specific dermatomal distribution. We evaluated the presence of functional disability using the modified Aminoff and Logue Scale of Disability (ALS) ${ }^{14}$ and the modified Rankin Scale. ${ }^{15}$ The scores were based on the records of the patients' symptoms and neurologic examinations, which were described by neurologists not directly involved in treatment.

\section{Imaging Diagnosis}

SEDAVFs were defined as arteriovenous shunts located in the epidural space, fed by multiple epidural arterial branches and draining first to the epidural venous pouch and then into the paravertebral vein and, in some cases, into the intradural vein. Direct, high-flow, single-hole fistulas between the vertebral artery and the vertebral venous plexus (also known as vertebrovertebral fistulas) or paravertebral fistulous lesions in the extradural space were excluded from this study. ${ }^{6}$

The venous drainage pattern of the SEDAVFs was analyzed on the basis of the $2 \mathrm{D}$ angiographic findings to determine whether there was retrograde intradural reflux through the radicular vein. MR imaging, CT, or dual 3D rotational angiography or a combination of these was used to demonstrate bone involvement of the SEDAVFs. ${ }^{13}$ The "osseous type" was defined as an SEDAVF with bone involvement, such as bone erosion, osteolytic destruction, or compression fracture (Fig 1).

Spinal MR imaging was performed for initial assessment of the disease. Axial and sagittal images of T1- and T2-weighted sequences with or without contrast enhancement were obtained with $1.5 \mathrm{~T}$ or $3 \mathrm{~T}$ systems. The presence and extent of spinal cord edema, perimedullary flow voids, and any epidural lesion that

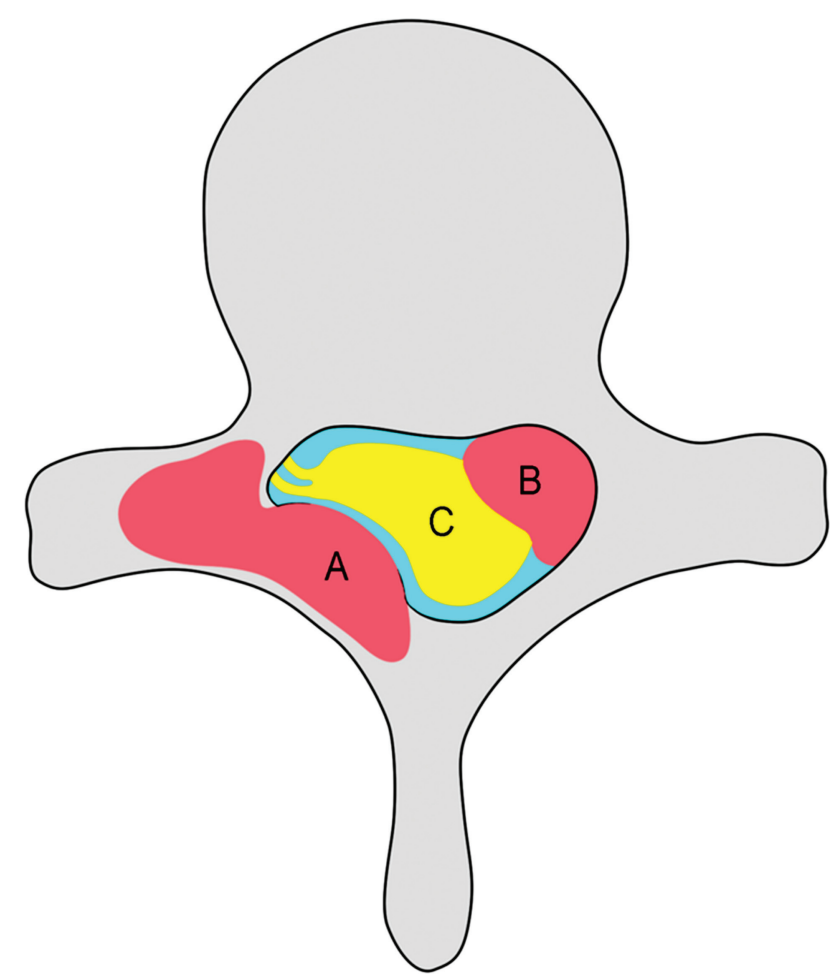

FIG 1. Schematic diagram of a spinal epidural arteriovenous fistula. An osseous SEDAVF shows bone involvement and compression of the nerve root or the spinal cord by bulging with cortical erosion $(A)$. A nonosseous SEDAVF shows engorgement (fistulous sac or pouch) of the epidural vein $(B)$ within the spinal canal compressing the spinal cord (C).

compressed the nerve root or thecal sac were assessed on imaging. Patients who needed imaging evaluation clinically after treatment underwent follow-up MR imaging.

Spinal digital subtraction angiography (Artis zee; Siemens, Erlangen, Germany) was used for localization and characterization of the SEDAVFs. All possible feeders-including vertebral arteries, thyrocervical and costocervical trunks in the cervical lesions, and lateral and medial sacral arteries from internal iliac arteries in the lumbosacral lesions-and all segmental arteries were scrutinized. 3D rotational angiography further clarified the location of and relationship among the arterial feeders, fistulous sac (pouch), arterialized veins, and the point where intradural reflux occurred.

\section{Treatment}

Endovascular embolization was considered primarily when the vascular approach to the fistula appeared angiographically possible. There were 2 modes of treatment in which transarterial embolization (TAE) was used for nonosseous SEDAVFs; and transvenous embolization (TVE), for osseous SEDAVFs. The treatment strategy of nonosseous SEDAVFs was basically similar to that for SDAVFs: to occlude the shunt and the proximal drainage vein. The range of the embolization target was the point at which intradural reflux occurred, to obliterate retrograde venous drainage into the radicular vein leading to congestive venous myelopathy. The glue, a mixture of N-butyl-2-cyanoacrylate (Histoacryl ${ }^{\circledR}$; B. Braun, Melsungen, Germany) and iodized oil (Lipiodol ${ }^{\circledR}$; Guerbet, Roissy, France), was used at the wedged position via a transarterial approach. ${ }^{16}$ The TVE was used when multiple arterial feeders converged on the fistulous sac in the osseous defect of the vertebral column and the fistulous sac could 


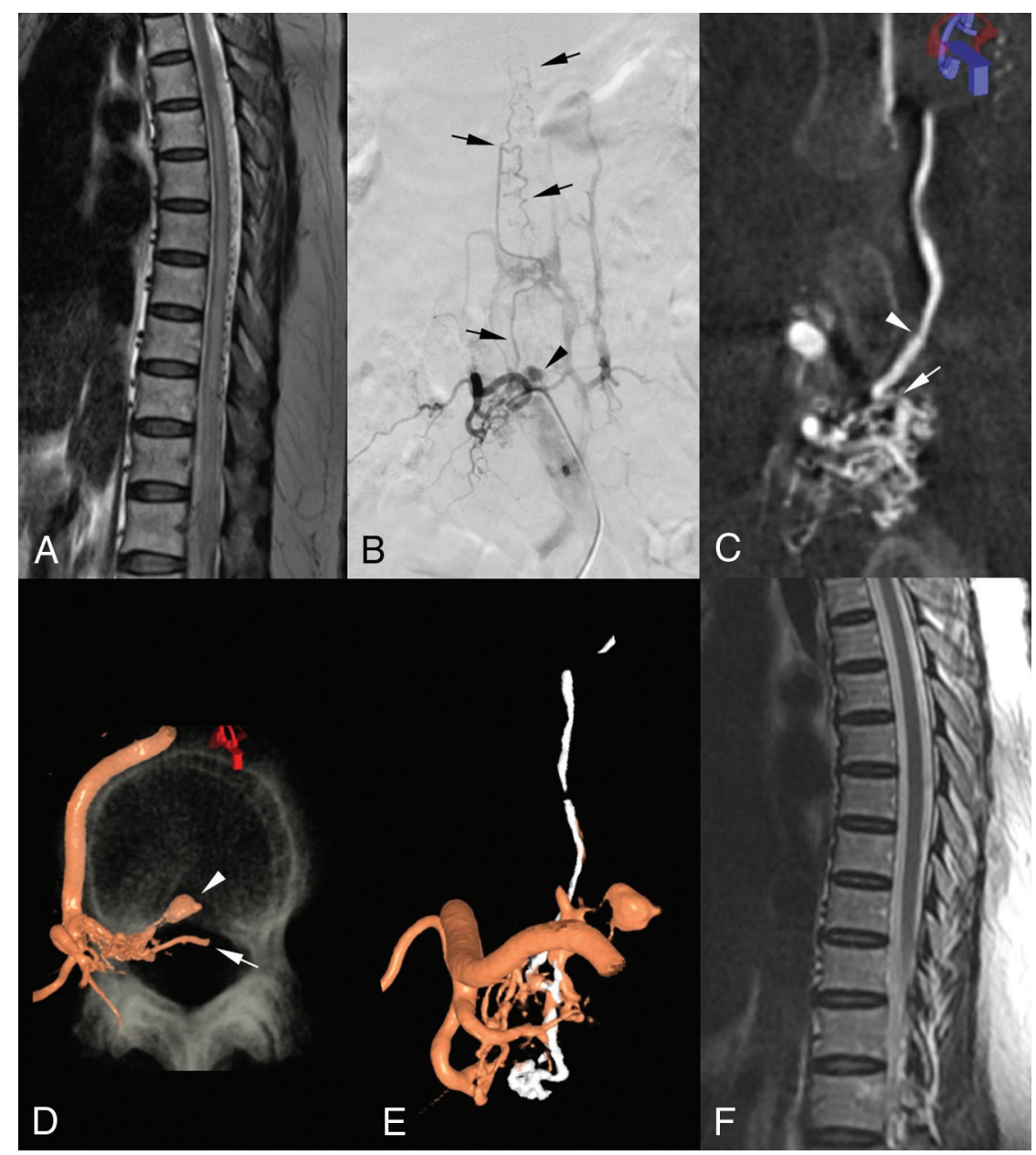

FIG 2. Spinal epidural arteriovenous fistula (perimedullary venous drainage) in a 63-year-old woman (case 4). A, Sagittal T2-weighted MR imaging reveals diffuse spinal cord edema up to the T5 level and multiple signal voids in the posterior aspect of the cord. $B$, Right lumbar arteriogram shows an arteriovenous fistula at the L2 level with multiple fine feeding arteries and early venous drainage to the epidural and paravertebral venous plexuses and to intradural veins (arrows). A small venous sac is visible around the fistula (arrowhead). C, 3D rotational angiogram shows the anatomy in detail where the intradural reflux originated (arrow). Note the focal narrowing of the vein where it penetrates the dura (arrowhead). D, Volume-rendering image demonstrates the epidural location of the fistula and the venous pouch (arrowhead). An intradural course of the radicular vein is also visible (arrow). E, Postembolization $3 \mathrm{D}$ angiogram confirms the presence of radiopaque glue in the fistula and along the intradural vein (white areas). F, Follow-up MR imaging 2 months later shows that the diffuse cord edema and the perimedullary vessels have disappeared. up. We evaluated the outcomes by comparing the scores at initial status with those at the most recent follow-up. We used STATA, Version 13.0 (StataCorp, College Station, Texas) to perform statistical analysis. All data were organized as the mean and range of continuous variables and as the number and percentage of categoric variables. Statistical significance $(P<.05)$ among the scores was determined with a Student $t$ test or the Wilcoxon rank sum test (if the assumption of normality was violated on the Shapiro-Wilk normality test).

\section{RESULTS}

\section{Baseline Characteristics}

A general overview of the patients' information is presented in the On-line Table. Of the 13 patients, 10 were male and 3 were female; the mean age was 49.6 years (range, 16-67 years). The mean duration from symptom onset to diagnosis was 3.6 months (range, 1 week to 24 months). Bilateral lower extremity weakness and sphincter dysfunction were typical manifestations of congestive myelopathy, which was noted in 7 patients with intradural venous drainage. Of the 6 patients without intradural reflux, 4 patients had radiculopathy or compressive myelopathy, which manifested mostly with pain, weakness, and paresthesia along the particular dermatome. The other 2 patients had only pain without neurologic symptoms. Three patients had a history of trauma (ie, case 1: T12 compression fracture due to a fall 3 years before; case 7: L1 compression fracture due to fall 3 years before; case 13: a fall 2.5 years before without vertebral fracture). be approached via a transvenous route through the epidural vein. Various types of detachable and pushable coils were used for TVE.

"Complete occlusion" was defined as disappearance of the fistula or shunted vein and an obliteration of the intradural venous drainage by disconnecting the fistulous sac with retrograde radicular venous drainage in the SEDAVF with congestive venous myelopathy (Fig 2). "Partial occlusion" was defined as having residual retrograde flow into the retrograde intradural vein, especially in SEDAVFs with congestive venous myelopathy or delayed opacification of the fistula or shunted veins on the venous phase with prominent contrast stasis in SEDAVFs with radiculopathy without retrograde intradural venous drainage.

\section{Outcome and Statistical Consideration}

The patients' neurologic symptoms and functional abilities were recorded with the use of the ALS and mRS scores on every follow-

\section{Imaging Diagnosis}

Initial MR imaging, which was performed in all 13 patients, showed abnormal findings. Both spinal cord edema and perimedullary flow voids were noted in 7 patients with congestive myelopathy. Of the 6 patients without intradural reflux, 1 patient demonstrated focal signal change in the spinal cord, caused by the mass effect of the epidural vascular lesion. The other 5 patients demonstrated only epidural vascular lesions without spinal cord involvement. Among 5 patients who had an osseous type of SEDAVF, 4 patients underwent CT, which showed bone involvement at the fistula level.

2D and/or 3D spinal DSA confirmed the presence of epidural arteriovenous fistulas in all 13 patients. The lesions were categorized into 2 groups according to the existence of intradural reflux. Seven patients showed intradural drainage through the radicu- 

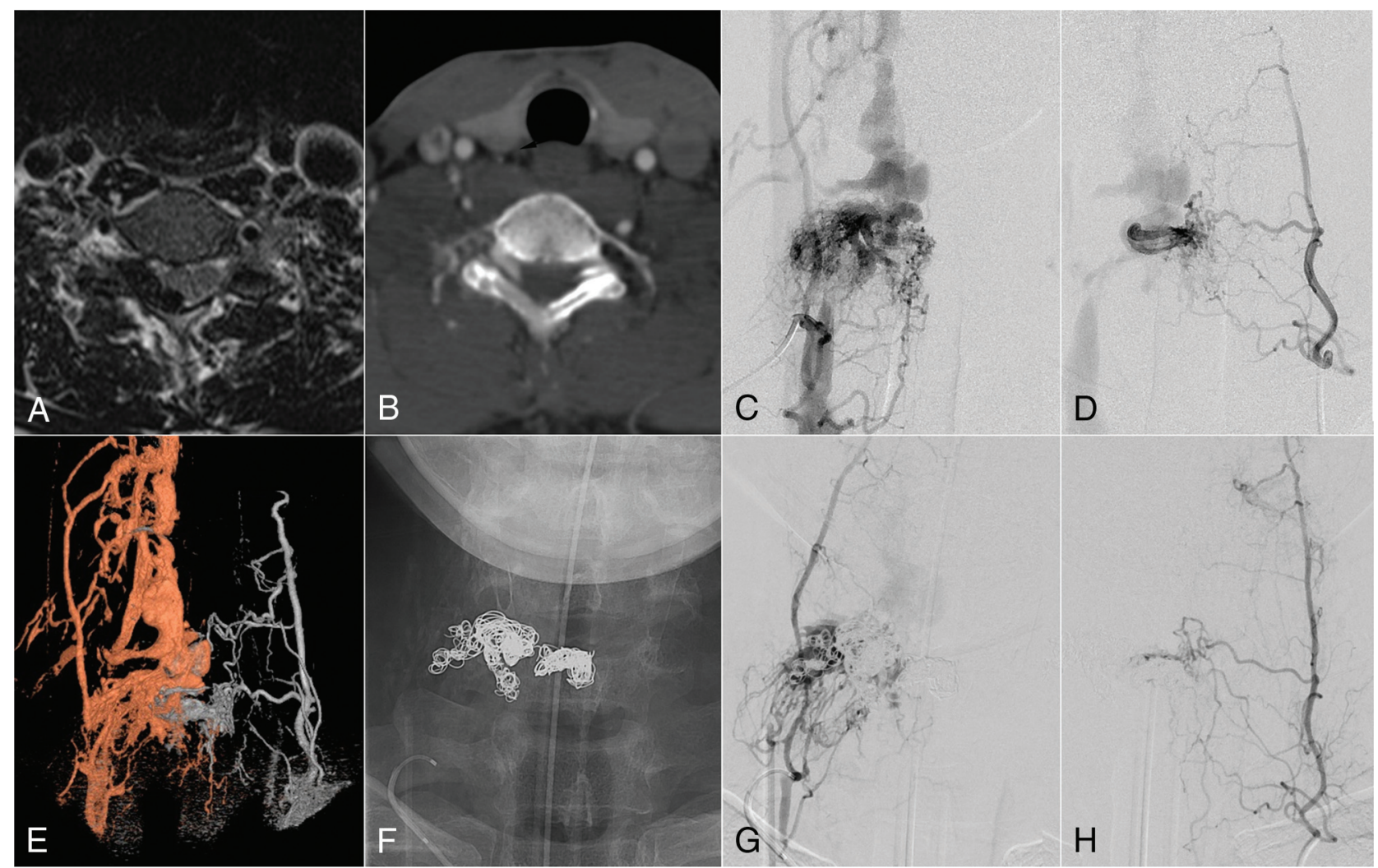

FIG 3. Osseous spinal epidural arteriovenous fistula in a 57-year-old man (case 9). A, T2-weighted axial MR image reveals a well-defined lesion with dark signal intensity in the right epidural space at the C6 level. $B, C T$ scan at the corresponding level shows adjacent bone destruction of the right lamina and spinous process of the $C 6$ vertebra that resulted from the well-enhanced epidural lesion. $C$ (right) and D (left), Deep cervical arteriograms. A large arteriovenous fistula with multiple arterial feeders is visible at the C6 level. E, 3D fusion image demonstrates that the feeders from both sides converge on a focal region - the epidural venous plexus and internal jugular veins-from which venous flow drains exclusively via extradural veins. F, After 2 sessions of transvenous coil embolization, the fistula flow has almost completely disappeared ( $G$ and $H)$.

lomedullary and perimedullary veins. Of those 7 , only 3 patients had solely intradural drainage without any extradural component. The distribution of the fistulas in the intradural reflux group were thoracic $(n=2)$, lumbar $(n=3)$, and sacral $(n=2)$, while that of the pure extradural group was cervical $(n=3)$ and lumbar $(n=3)$. Adjacent bone involvement of the SEDAVF was demonstrated in 5 patients on $3 \mathrm{D}$ angiography.

\section{Treatment}

Among the 13 patients with SEDAVFs, 10 patients received endovascular embolization, 1 patient underwent an operation after the endovascular treatment was aborted, and 2 patients refused treatment due to tolerable symptoms (On-line Table). Endovascular embolization comprised TAE in 7 patients (Fig 3) and TVE in 3 patients (Fig 4). TAE was selected in all patients with nonosseous SEDAVFs. The embolic material used in TAE was glue in all patients and additional coils in 1 patient. Transvenous coil embolization was performed in 3 patients with osseous SEDAVFs. Complete obliteration of the fistula or intradural drainage vein was achieved in all 6 patients with congestive myelopathy. Among the patients without intradural venous reflux, complete occlusion was possible in 1 patient, and partial occlusion, in 3 patients because complete obliteration was not usually required. Surgical disconnection of the intradural drainage vein was successfully performed in the patient in whom the endovascular approach

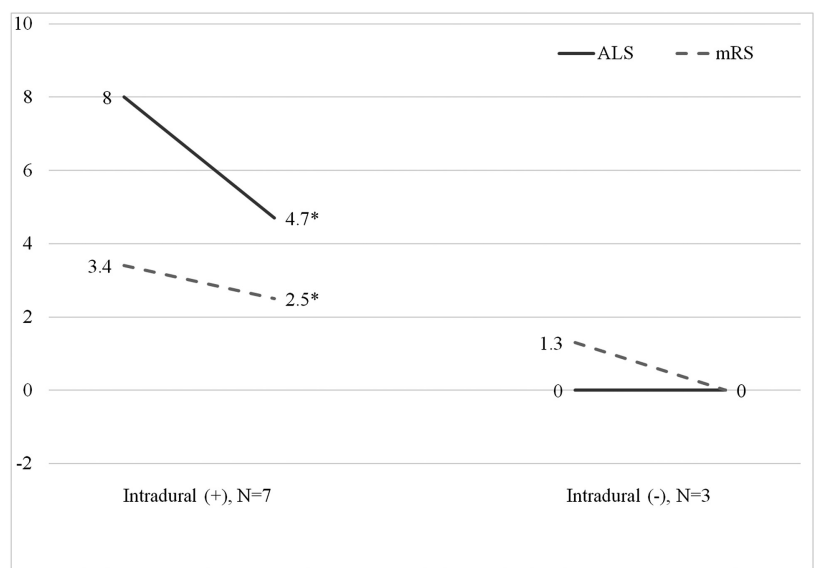

FIG 4. Outcomes in patients according to each scoring system and the presence of intradural reflux. The mean scores of the initial and follow-up evaluations are shown. Asterisks indicate statistically significant improvement at follow-up.

failed due to complex vascular anatomy. There was no periprocedural complication in all treated cases.

\section{Outcomes}

Among 11 patients who underwent either endovascular treatment $(n=10)$ or an operation $(n=1)$, the mean duration of follow-up after treatment was 23 months (range, 1-63 months; 
median, 19 months). The other 2 patients without treatment were lost to follow-up. The mean ALS and mRS scores were significantly decreased at follow-up in the intradural reflux group (8.0 versus $4.7, P=.01 ; 3.4$ versus $2.5, P=.016$, respectively) (Fig 4). On the other hand, the group without intradural reflux showed a tendency toward decreasing scores without significance. The overall scores were higher in the patients with intradural reflux in all the grading systems. The scores of ALS were zero in the patients without intradural reflux at both initial assessment and follow-up. Symptoms and functional status improved, or at least did not change, after treatment in all except 1 patient (case 5). In this patient, mild lower back pain developed 4 months after treatment despite improvement in other symptoms.

\section{DISCUSSION}

Endovascular treatment is currently the favored method of SEDAVF treatment; the use of endovascular treatment has been reported in approximately two-thirds of pertinent studies and case reports. ${ }^{2}$ The rates of complete or near-complete occlusion of the SEDAVF with endovascular treatment ranged from $73.3 \%$ to $94.4 \%$, and the rates of symptom improvement ranged from $62.5 \%$ to $91 \% .{ }^{1-3}$ Our study also demonstrated an excellent occlusion rate (100\%) and good treatment outcomes (91\%). Intradural venous drainage, noted in $53.8 \%{ }^{7}$ of the 13 patients in this study, was seen with variable frequency in previous studies $\left(27.0 \%^{2}\right.$ to $\left.74.5 \%{ }^{4}\right)$. In this study, ALS scores were zero in all patients without intradural venous drainage except for 1 patient who had mild leg weakness caused by compressive myelopathy.

Although endovascular treatment produced good outcomes in most patients in this study, 1 patient (case 7) could not recover from the congestive myelopathy symptoms, even after complete occlusion of the shunt and improved cord edema at 1-month follow-up MR imaging. Although further follow-up is required, this intractable case may be attributed to a 24-month delay in diagnosis and the spinal cord possibly being irreversibly damaged as in patients with SDAVFs. ${ }^{6}$ In the patient who finally underwent an operation, the endovascular approach was ruled out by the complicated vascular anatomy in which the microcatheter tip could not reach the appropriate position to occlude the shunt. An operation was a good alternative in this patient, and symptoms improved as in patients with SDAVFs. ${ }^{17}$

The vascular structures surrounding the lesion must be analyzed thoroughly to determine appropriate treatment plans. We routinely obtain a $3 \mathrm{D}$ rotational spinal angiogram to better understand the relationships among the feeders, fistulas, and draining veins. ${ }^{13}$ Accurate localization of regurgitation from the epidural venous plexus to the intradural vein is especially crucial to treat the lesion with intradural reflux because during TAE, the liquid embolic material must penetrate the intradural vein to cure the disease. The microcatheter tip should be placed at the appropriate point from which the preferential flow goes through the intradural vein before embolic material is injected to achieve this goal. We used glue for TAE because it is easy to control, injection time is relatively short, and it has better visibility than Onyx (Covidien, Irvine, California). ${ }^{8,16}$ The use of Onyx for SEDAVF embolization has been limited by difficulty in achieving venous penetration. ${ }^{16}$
This study included 5 cases (38.4\%) of osseous SEDAVFs, even though only a few cases of SEDAVFs with bone involvement have been reported previously. ${ }^{18-20}$ The mechanisms of formation of the bone lesion and its clinical significance are uncertain. When planning a treatment option, identification of the osseous type can be important. Because Osseous SEDAVFs tend to be a highflow shunt with large epidural venous spaces, a transvenous approach may be possible. ${ }^{8}$ In our cases, 3 underwent TVE, 1 underwent an operation, and the other one was under observation because the symptoms were tolerable. Although trauma was suggested as a cause of SEDAVFs, especially in the osseous type, ${ }^{19,20}$ only 1 patient in our study (case 1) was confirmed to have a history of trauma in which a $\mathrm{T} 12$ compression fracture was caused by a fall 3 years before the initial presentation. Because the patient's symptoms developed after the trauma and the fistula occurred at the same level, we assumed that the SEDAVF could have been the result of the trauma, despite the long interval. A history of previous trauma was also noted in 2 other patients (cases 7 and 13) with the nonosseous type of SEDAVFs in our study.

A limitation of this study could be that the number of patients was very small because of the rarity of SEDAVFs. Diagnosing the patients only through imaging findings without pathologic confirmation could be another limitation. Follow-up spinal MR imaging or DSA was not performed in all patients because we did not do routine imaging studies as long as symptoms improved. Longterm follow-up will be required because not all patients were followed up for a sufficient time.

\section{CONCLUSIONS}

SEDAVFs were found in $13(11.7 \%)$ patients of the all spinal vascular malformations in our center. The presenting patterns were diverse, from tolerable symptoms $(n=2)$ and radiculopathy $(n=$ $5)$ to congestive venous myelopathy $(n=7)$. There is overlap of symptoms in 1 patient (No. 11). The intradural venous reflux was identified in all 7 patients with congestive venous myelopathy. Osseous SEDAVFs were observed in 5 patients in whom the fistulas were successfully controlled by TVE $(n=3)$ except 2 patients who underwent an operation $(n=1)$ and only clinical observation $(n=1)$. Nonosseous SEDAVFs were observed in 8 patients (intradural reflux in 5) in whom obliteration of the fistula including intradural venous drainage was achieved by TAE, except 1 patient who refused treatment due to tolerable symptoms and wanted clinical observation. The SEDAVFs were successfully treated in 11 patients by endovascular embolization $(n=10)$ and an operation $(n=1)$. After 19 months of median follow-up, most patients showed symptom improvement after treatment.

\section{REFERENCES}

1. Burkhardt JK, Safaee MM, Clark AJ, et al. Sacral epidural arteriovenous fistulas: imitators of spinal dural arteriovenous fistulas with different pathologic anatomy-report of three cases and review of the literature. Acta Neurochir (Wien) 2017;159:1087-92 CrossRef Medline

2. Huang W, Gross BA, Du R. Spinal extradural arteriovenous fistulas: clinical article. J Neurosurg Spine 2013;19:582-90 CrossRef Medline

3. Nasr DM, Brinjikji W, Clarke MJ, et al. Clinical presentation and treatment outcomes of spinal epidural arteriovenous fistulas. J Neurosurg Spine 2017;26:613-20 CrossRef Medline

4. Kiyosue H, Matsumaru Y, Niimi Y, et al. Angiographic and clinical 
characteristics of thoracolumbar spinal epidural and dural arteriovenous fistulas. Stroke 2017;48:3215-22 CrossRef Medline

5. Ramanathan D, Levitt MR, Sekhar LN, et al. Management of spinal epidural arteriovenous fistulas: interventional techniques and results. J Neurointerv Surg 2014;6:144-49 CrossRef Medline

6. Park JE, Koo HW, Liu H, et al. Clinical characteristics and treatment outcomes of spinal arteriovenous malformations. Clin Neuroradiol 2018;28:39-46 CrossRef Medline

7. Jung SC, Song Y, Cho SH, et al. Endovascular management of aneurysms associated with spinal arteriovenous malformations. $\mathrm{J} \mathrm{Neu-}$ rointerv Surg 2018;10:198-203 CrossRef Medline

8. Chul Suh D, Gon Choi C, Bo Sung K, et al. Spinal osseous epidural arteriovenous fistula with multiple small arterial feeders converging to a round fistular nidus as a target of venous approach. AJNR Am J Neuroradiol 2004;25:69-73 Medline

9. Lim SM, Choi IS. Spinal epidural arteriovenous fistula: a unique pathway into the perimedullary vein-a case report. Interv Neuroradiol 2009;15:466-69 CrossRef Medline

10. Krings T, Mull M, Bostroem A, et al. Spinal epidural arteriovenous fistula with perimedullary drainage: case report and pathomechanical considerations. J Neurosurg Spine 2006;5:353-58 CrossRef Medline

11. Lee CS, Pyun HW, Chae EY, et al. Reversible aggravation of neurological deficits after steroid medication in patients with venous congestive myelopathy caused by spinal arteriovenous malformation. Interv Neuroradiol 2009;15:325-29 CrossRef Medline
12. Brinjikji W, Yin R, Nasr DM, et al. Spinal epidural arteriovenous fistulas. J Neurointerv Surg 2016;8:1305-10 CrossRef Medline

13. Suh DC, Kim HS, Baek HJ, et al. Angioarchitecture of spinal dural arteriovenous fistula: evaluation with $3 \mathrm{D}$ rotational angiography. Neurointervention 2012;7:10-16 CrossRef Medline

14. Aminoff MJ, Logue $\mathrm{V}$. The prognosis of patients with spinal vascular malformations. Brain 1974;97:211-18 CrossRef Medline

15. van Swieten JC, Koudstaal PJ, Visser MC, et al. Interobserver agreement for the assessment of handicap in stroke patients. Stroke 1988; 19:604-07 CrossRef Medline

16. Suh DC, Cho SH, Park JE, et al. Induced-wedge technique to improve liquid embolic agent penetration into spinal dural arteriovenous fistula. World Neurosurg 2016;96:309-15 CrossRef Medline

17. Adrianto Y, Yang KH, Koo HW, et al. Concomitant origin of the anterior or posterior spinal artery with the feeder of a spinal dural arteriovenous fistula (SDAVF). J Neurointerv Surg 2017;9:405-10 CrossRef Medline

18. Suh DC, Kim JH, Lee MS, et al. Penetration difference of N-butyl2cyanoacrylate into the nidus in the embolisation of brain arteriovenous malformation. Interv Neuroradiol 1998;4:63-74

19. Jin YJ, Chung SK, Kwon OK, et al. Spinal intraosseous arteriovenous fistula in the fractured vertebral body. AJNR Am J Neuroradiol 2010; 31:688-90 CrossRef Medline

20. Ou CH, Wang HK, Yang TH, et al. Spinal intraosseous epidural arteriovenous fistula with perimedullary drainage obliterated with Onyx embolization: case report. J Neurosurg Spine 2015;23:250-53 CrossRef Medline 